\title{
Skill Shortage versus Subject Choice: Case of Pakistan
}

\author{
ATIQ-UR-REHMAN, HAFsA ANIS and SAUD AHMED KHAN
}

\section{INTRODUCTION}

The economics is to tell how to make choices when there are multiple options. It is assumed to propose a portfolio to engage the limited resources in order to optimise certain outcomes. It is widely believed that Higher Education is an important determinant of economic growth. Therefore a suitable portfolio of experts into various subjects can optimise the economic growth. The effect of education on economic outcomes is widely recognised, [see Stevens and Weale (2003) for a comprehensive survey]. However education per se is not sufficient to optimise the economic outcomes. The subject wise distribution of the experts is very important. Therefore we need to decide what how much experts to be produced in various subjects.

We would start with the example of two countries, Japan and Turkey to show that how big difference can be made by the decision of choice of field of specialisation. The two countries were allies in the World War II. An excellent analysis of post World War II development in the two countries is provided by Binnaz (2006). Both countries were at similar position at the end of World War II with respect to their economic and social conditions. The two countries realised role of education in the development and decided to promote education. However they were having different priorities on their educational policy agenda. Turkish emphasised on education of literature, art and music etc. For any popular novel written in English, you would find its translation in Turkish as well. At the same time, Japan emphasised on education of Mathematics, Technology and Engineering. The difference their decisions made is quite evident from their recent economic and social status in the world.

The decision of filed of study, especially higher studies carries high costs for society and for individuals. It is the most important decision in an individual's life, since future economic position and social status of individual depends on this decision. The cost of production of a $\mathrm{PhD}$ is in millions, either paid by individuals or by the governments. If this investment is pre-planned according some national policy, this would produce better results than un-planned investment. One can formulate a suitable

Atiq-ur-Rehman <ateeqmzd@yahoo.com> is PhD Scholar (Econometrics), IIIE, International Islamic University, Islamabad. Hafsa Anis is Lecturer, National Institute of Computer Science and Technology, Muzaffarabad. Saud Ahmed Khan <saudak2k3@yahoo.com> is Lecture, IESE, NUST, Islamabad and PhD Scholar (Econometrics), IIIE, International Islamic University, Islamabad. 
portfolio of required skills that optimise the economic growth of the nation within the constraints of available budget. An educational policy to achieve this portfolio would be more helpful for the nation on the way of economic progress. Therefore for a developing country with limited resources, it is very important to analyse whether current trend of choice of field of study is optimal or near optimal according to the requirements of a nation.

Economists have studied the impact of labour market conditions and some other social and economic factors on the choice of field of study [e.g., Kelly, Connell, and Emer (2008), Kelly, Connell, and Smyth (2008)]. An equally important question is; what would be the impact of current pattern of enrolment in different fields of studies on the macroeconomic indicators in future? But unfortunately, we were unable to find any significant research in this direction after several search attempts in Google and other search facilitators. There are several studies discussing skill shortage in some countries e.g. Skill Shortage Indicator Report of New Zealand. This report is intended to recommend a visa policy for the New Zealand. Australia has formulated a national policy to deal with the skill shortage ('What is skill shortage', Local government skill shortage steering committee report, 2006). The purpose of this policy is train more labourers and professionals, since Australia is facing shortage of labour supply due 'Ageing', a global demographic phenomenon. House of Commons of Britain approved a skills development policy for the students age 14-19 (6th report of session 2004-05, House of Commons, Britain). This policy is intended to improve basic skills of mathematics and sciences among the students age 14-19 and this policy has nothing to do with the issue of subject choice.

Current study is an attempt to motivate academia to direct their attention to the problem we outlined above: Is the current pattern of choice of field of studies optimal with regard to national interests? If not, than what are blueprints of optimal pattern? Is there need of government intervention in such choice? How we can motivate individuals to opt the fields of study in accordance with national interests?

Since this is preliminary attempt to motivate research according to outlines traced above, we may have made many mistakes and we do not emphasis on validity of arguments we presented. However, we believe that the question we highlighted above is worth considering by the policy-makers and is able to create significant impact on future economic outcomes.

\section{SKILL SHORTAGE IN DEVELOPING AND DEVELOPED COUNTRIES}

As we have mentioned, we were unable to find any study discussing the impacts of current pattern of the enrolment of students in higher education on future economic outcomes. In fact the problem of mismatch between skill demand and supply is less serious problem for the developed countries. The shortage of skill will motivate more of foreign workers to move toward these countries. These foreign professional usually belong to developing countries with lower income level and does not create any burden on host country since their demand is less than existing wage rate in the host country. The host country gets the advantage of cheap skill supply. Based on the skill shortage indicators, some countries (e.g. New Zealand) have different visa policies for people belonging to different professions. But there is no comprehensive to discuss the pattern of 
enrolment and train the students accordingly. However for the developing countries, hiring a foreign expert is much more expensive than from recruiting local experts. Therefore the problem needs serious attention from the developing countries than from advanced countries.

\section{OPTIMISING HIGHER EDUCATION IN PAKISTAN}

In past few years, Pakistan has introduced extraordinary incentives to promote higher education. These attempts brought revolutionary changes in the enrolment in higher education and the output produced. Definitely the Govt. is paying high costs for the incentives it introduced. However the job of an economist is to propose a portfolio such that the output can be optimised with given level of inputs. In this regard we investigate some very important questions: (i) whether or not it is possible to create more effective brain force with the same resources we currently employ, and (ii) is the current allocation pattern of enrolment compatible with the requirements of nation in near future.

The current study is an attempt to search the answers for similar questions. In particular, we take the question of enrolment in various subjects and analyse whether the enrolment pattern allocates appropriate share for various skills. If not than what are the reasons and how can effective intervention be made to remove any mismatch/inefficiency that exists.

\section{The Data Problems}

Unfortunately, the data is not available easily on the subject wise breakup of the enrolment. We utilise two sources for the data on subject wise enrolment. These two sources are the National Educational Census and the Higher Education Commission of Pakistan, who provide data on the subject wise enrolment for 2005 only. Few figures are obtained from Federal bureau of Statistics and from WDI-CD ROM.

\section{THE CURRENT PATTERN OF SUBJECT CHOICE}

According to the National Educational Census of Pakistan (2005), there were 785,249 students enrolled in the institutes of higher learning allocated into different subjects. The percentage of students allocated into different subjects is illustrated in Table 1.

Table 1

Enrolment in Institutes of Higher Learning in Pakistan, 2005

\begin{tabular}{lcclcc}
\hline Fine Arts & 10913 & $1.4 \%$ & Pharmacy & 11183 & $1.4 \%$ \\
Agriculture & 9485 & $1.2 \%$ & Veterinary & 2956 & $0.4 \%$ \\
Law & 22577 & $2.9 \%$ & Engineering & 43801 & $5.6 \%$ \\
Education & 37540 & $4.8 \%$ & Information Technology & 37635 & $4.8 \%$ \\
Home Economics & 7773 & $1.0 \%$ & Commerce & 146328 & $18.6 \%$ \\
Medical & 19457 & $2.5 \%$ & Business Administration & 39186 & $5.0 \%$ \\
Nursing & 7843 & $1.0 \%$ & Accountancy & 14042 & $1.8 \%$ \\
Science Total & 117949 & $15.0 \%$ & Arts Total & 256581 & $32.7 \%$ \\
Grand Total & 785249 & $100.0 \%$ & & \\
\hline
\end{tabular}

Source: National Education Census, 2005. 
Maximum number of students have opted Arts as field of study, and the Commerce comes second. The most surprising number in the table is the enrolment in agriculture related degrees. Agriculture sector is the largest sector in Pakistan providing employment to approximately 48 percent of total employed labour force. ${ }^{1}$ But the enrolment in this sector is just 1.4 percent of total enrolment.

If we divide the subjects into categories according to sectors of economy, Fine Arts, Law, Home Economics, Information Technology, Commerce, Business Administration, Accountancy, Science Total, Arts Total can be included into pro-services subjects. These subjects attracted about 60 percent of total enrolment. Another surprise is that, only fine arts have attracted 1.4 percent of total enrolment compared to 1.2 percent attracted by the agriculture.

The picture is almost similar if we look at the trend in enrolment in advanced studies. Table 2 illustrates enrolment in advanced studies (MPhil and $\mathrm{PhD}$ ) in different field of studies.

Table 2

Enrolment in MPhil/PhD in various Disciplines, 2005

\begin{tabular}{lcclcc}
\hline Agriculture & 528 & $4.1 \%$ & Law & 332 & $2.6 \%$ \\
Arts and Design & 26 & $0.2 \%$ & Medical and Health Science & 168 & $1.3 \%$ \\
Biology & 1118 & $8.7 \%$ & Pharmacy & 218 & $1.7 \%$ \\
Business Administration & 494 & $3.9 \%$ & Public Administration & 17 & $0.1 \%$ \\
Chemistry & 721 & $5.6 \%$ & Science Total & 1136 & $8.9 \%$ \\
Commerce & 23 & $0.2 \%$ & Social Science Total & 3980 & $31.1 \%$ \\
Computer Science and I.T. & 769 & $6.0 \%$ & Veterinary and Husbandry & 329 & $2.6 \%$ \\
Engineering & 409 & $3.2 \%$ & Consolidated (subject breakup not & & \\
& & & available) & 2531 & $19.8 \%$ \\
Grand Total & 12,799 & $100.0 \%$ & & & \\
\hline
\end{tabular}

Source: Statistical Booklet of HEC, Pakistan.

Table 2 reveals that enrolment in agriculture related subjects in MPhil/PhD level is 4 percent which is more than the enrolment in the subject at B.A./B.Sc. level (1.2 percent). This implies that the students having agriculture degrees are more likely to continue their education for higher degrees. There may be two explanations for this observation; first students find it more charming to continue education if they are studying agriculture. Second, the students find it difficult to have a job after their B.A./B.Sc and therefore they decide to continue study. The enrolment in business administration and agriculture is about 4 percent students. Enrolment in management related degrees and commerce is much smaller at $\mathrm{PhD}$ level than from graduation level. Students choosing commerce at graduation level are 18 percent whereas at $\mathrm{PhD}$ level its only 0.2 percent. This means the trend to continue study toward higher education is very low for the students enrolling in these subjects. Again there may be two reasons for this observation: either the students get reasonable jobs after their Bachelor degree and discontinue to study further or the students does not find it more attractive to have a higher degree.

${ }^{1}$ Source: World Development Indicators (WDI), 2008 CD-ROM. 


\section{SUBJECT CHOICE AND NATIONAL INTERESTS}

Now we investigate very important question; whether current pattern of enrolment in higher education compatible with the national interests? This question can be answered only indirectly, natural measure of compatibility of skills with national needs would be the gap between need of skills and supply of skills. We are intentionally using the word 'need' instead of 'demand' of skills, since demand does not always insures fulfilment of needs in the real world. A poor patient may not affect the demand of an expensive life saving medicine although he seriously needs it.

The shortage of a skill in a subject or sector is an indicator of needs of nation and shortage of skill is approximated by different indicators. Some countries e.g. New Zealand [Department of Labour, New Zealand, 2006] have made arrangements to develop the measures of shortage of skills. The following are popular measures of shortage of skills:

- Vacancy fill rates.

- The relative volume of vacancies.

- Evidence of excessive wage pressures.

- Assess the occupations exposure to product and labour market competition.

The data availability for these indicators requires sufficient resources and time which we plan for future. The indicators we use to analyse shortage or otherwise of skills are the efficiency, productivity, import/exports related to profession and the cross country comparison.

\section{Agriculture}

Our first focus is the agriculture sector, since it is the largest sector of economy and it provides employment to about half (48 percent) of employed labour force in Pakistan. As reported in Table 1, agriculture sector has attracted only 1.2 percent of the students in universities. There is huge gap between the employment generated by agriculture sector and the students seeking university education in this profession. The gap is natural indicator of shortage of skills in the profession. However some people may argue that farming does not demands a degree and therefore the gap is no surprise. But this argument is not true since Pakistan is a big importer of seeds pesticides, fertiliser etc. for which Pakistan has resources to produce domestically. This implies Pakistan has lack of expertise to domestically these products. Here we summarise some indicators helping to assess the skill shortage in this sector.

The first indicator indicating shortage of skills in agriculture sector is the agricultural value added per worker. The percentile rank of Pakistan ${ }^{2}$ with respect to this indicator is 32nd indicating that 68 percent countries of the world are producing more with a worker than Pakistan. This indicates that our farmers do not have enough skills in farming and therefore they are producing less.

The second indicator is imports related to agriculture. Despite of being an agricultural country, Pakistan imports seeds, fertilisers, tractors and pesticides from foreign. Pakistani imports related agriculture and live stock in 2007-08 were about Rs

\footnotetext{
${ }^{2}$ Data Source: WDI CDROM.
} 
115,459 million. ${ }^{3}$ It is important to note that for many of these imports, Pakistan have domestic production of necessary inputs. Therefore the imports reflect the deficiency of skills in the agriculture sector.

Therefore these indicators reflect there is extensive need of skills in order to achieve international level of productivity from a worker, and also to reduce the imports related to agriculture that can be produced domestically.

\section{Live Stock}

Similar to agriculture sector, livestock provide livelihood to a large number of individuals in Pakistan. Pakistan is a big producer of milk and meat and leather. Products related to leather and dairy formulate a big industry in Pakistan. According to National Educational Census 2005, only 2954 people were enrolled in the veterinary/animal science institutes, which is 0.4 percent of the total enrolment. However, despite having lot of individuals involved in livestock related business, large number of diary products are imported in Pakistan. Imports related to livestock during 2007-08 were about 121,756 million rupees. This reflects that there is heavy need of skill in the live stock sector as well.

\section{Manufacturing}

Next sector that we analyse is manufacturing sector. We think that there is no need to present data to convince that we need skills in manufacturing sector. Pakistan is importing a lot of things for which raw material is domestically produced. The shortage of skills is better reflected by quantity of import items for which raw material is available in the country. Pakistan's imports of manufactured goods during 2007-08 were about 238,769 million rupees.

\section{Medical}

The professions related to medical (including Nursing, Pharmacy and Dental Surgery) attracted about 4.9 percent of the students at junior level and about 3 percent at $\mathrm{MPhil} / \mathrm{PhD}$ level. The shortage of skill in medical sector is estimated by the indicator 'Physician Per 1000 people'. Average number of physicians in Pakistan in recent years has been 0.7 per 1000 people and the percentile rank of Pakistan with respect to this indicator is $41^{4}$ percent. This means about 60 percent of countries of world have more doctors than Pakistan. About 60 countries have more than 2 physicians for 1000 people.

\section{Engineering}

Engineering and poly technique attracted about 5.6 percent of total students at junior and 3.2 percent students at MPhil and PhD level. However an important thing we must consider is uneven demand of engineers in different engineering cadres. A large number of universities awarding engineering degree provide training in Computer, Software and Telecom Engineering etc. We would like to ask Overseas Employment to

\footnotetext{
${ }^{3}$ Federal Bureau of Statistics, 'Imports by Commodity/Group'.

${ }^{4}$ Data Source: WDI-CD ROM based on averaged data from 2000 to 2004.
} 
provide authentic figures on the professional affiliation of oversee Pakistanis. However our daily life experience tells that these skills re usually exported from Pakistan.

However Pakistan is big importer of advanced engineering skills in Civil, Mechanical and Electrical Engineering. Most of mega projects running in Pakistan e.g. Gawadar Port, Thur Coal Projects etc. are administered by foreign firms. This means there is still shortage of skills in the engineering related services.

Power Sector is perhaps the most demanding sector of Pakistan in future. Pakistan has lot of resources of renewable energy e.g. wind, hydro and solar energy. But most of infrastructure for these energies is imported in Pakistan, which is an indicator of severe shortage of skills in this sector. For an excellent overview of energy technologies in Pakistan, reader is referred to Awais, et al. (2008). This stimulating presentation recommend need of investment in the engineering skills related to turbine manufacturing.

\section{Business Administration, Commerce, Arts and Social Sciences}

Table 1 and Table 2 reveal that maximum number of students have opted Business Administration, Commerce and Social Studies for their careers. Business Administration and Commerce represent so called executive class and therefore attract a large number of students. Moreover teaching of these subjects does not require huge physical infrastructure therefore almost all universities in Pakistan have started programmes for MBA and BBA. We do not have authentic figures to present, however our daily experience tells that maximum number of skilled Pakistanis working abroad have specialisation in these subjects. These Pakistanis earn a lot of revenue for the country.

\section{REGULATING CAREER CHOICE}

Post-Keneyzian economics admits the role of governments in regulating economic activities to optimise certain economic outcomes. There are evidences on frequent failures of the phrases 'supply creates its demand' or 'the demand creates its supply', necessitating government intervention in the market. The career choice is an important decision having impact on economic outputs at individual and national level. We have presented evidences of a mismatch between national needs and allocation of students in different professional cadres. The question is whether Government needs to regulate the enrolment of students into different professions or not? It is obvious that production of a graduate or a $\mathrm{PhD}$ carries heavy cost for the society and for individuals. Governments are investing lot of resources to promote education. If we can produce more efficient brain force with currently employed resources, why not opt to do this? Pakistan has allocated more than 22 billion rupees in higher education in the last budget, and is spending in higher education since last decade. Despite of this huge investment, country does not have sufficient skills infrastructure to produce seeds and pesticides for the agriculture, the backbone of its economy.

Therefore our opinion is that Government must interfere in the enrolment pattern to make it suitable for the faster development of country. Government is investing lot of Capital in higher education. This investment does not differentiate between subjects with skill shortage and skill abundance. Most of people opt Commerce, Business Administration, Arts and Social Sciences for their career. Commerce and Business Administration are considered 
to produce so called executive skills, therefore attract a large number of students. Arts and Social Sciences comprise large number of subjects like Sociology, Pakistan Studies, History, Literature etc. These subjects also attract a large number of students. Actually, bachelors' degree in Arts/social science is considered as non-professional degree and the students who do not opt any professional degree in their bachelors, adopt Arts and Social Science for their higher degrees if they continue their education.

Agriculture, Medical and Engineering are the subjects with severe skill shortage. Medical and Engineering offer promising career to the students but existing infrastructure allows only limited number of students to be successful to get education in these subjects. Although agriculture is the backbone of the economy of Pakistan, it suffers severe skill shortage since it is less charming for the new students. Therefore there is need of educational reforms that can make the enrolment pattern more compatible with the national needs without any extra financial burden.

\section{SOME CONSIDERABLE REGULATORY MEASURES}

In order to regulate career choice, we need to understand the determinants of this choice. We can find several studies on the economics of career choice. Some of the determinants of career choice can not be regulated by the any regulating authority e.g. parent's profession, mental aptitude etc. However some of the determinants are in the control of Government. For example, availability of physical infrastructure, availability of teacher and trainers etc. can be used to regulate the career choice. Here we mention some of the determinants of career choice which can be regulated.

\section{Availability of Physical Infrastructure and Staff}

Availability of Physical Infrastructure and faculty is a big hurdle in the choice of many fields as a career for some of students. Every year large number of students fail to get admission in medical/engineering institutes because the institutions have resources to accommodate only a limited number of students. In Pakistan, there are only two institutes provide training in space/aeronautical engineering. Therefore despite willingness of many students to opt such disciplines, only few would succeed to get admission in these subjects. Pakistani culture puts some restrictions on the females to go far from there home places for education. Therefore the female students of remote areas would be unable to opt career of their choice because of unavailability of infrastructure in the vicinity.

Most of private sector universities and colleges provide education in Business Administration, Commerce, Computer Sciences and Social Sciences. Since Education in these fields requires minimum physical infrastructure, it is easy to start the education of these disciplines. The education of civil, mechanical and electrical engineering is demanding lot of physical infrastructure. Therefore despite the fact that lot of students would be willing to get admissions in these disciplines, only few private institutions have started recruitment in these fields.

\section{Career Counselling}

Most of students do not have any idea of the nature and scope of the discipline of the subject they are choosing for higher education. Most of students depend on their 
friends and seniors for getting information about the disciplines they are choosing (especially about 'scope' of subject) and these people themselves have imperfect information about the subject. This may be an ideal occasion when authorities can regulate the student's choice if there is some institution with facts and figures about the demand/need of market. This type of institution would reduce the tension of job search for the students since it is already playing a role to reduce the gap between market requirements and university's output.

\section{Incentive for Professions with Skills Shortage}

Premium to field of study is considered as most important determinant of the career choice. You would often see that some professions give a heavy reward to the student than from other profession. Salary of a management graduate from LUMS is much more than the salary of an agriculture graduate of Agriculture University Faisalabad. Therefore students would put management at their first priority, although there is equal need of agriculture graduates. Therefore if government wants to increase enrolment in a discipline which is important for nation but having lower market value, than government should increase the incentives for graduates in such discipline. For example, government may introduce special allowance for the graduates with severe skill shortage.

\section{Incentives for the Institutes}

As we have discussed above, most of institutes awarding engineering degrees provide training in Computer, Software and Telecom Engineering etc. This is because these disciplines require less quantity of physical infrastructure. Disciplines like Electrical, Mechanical and Space engineering require lot of infrastructure. Similarly education in medical is so costly that private sector can rarely afford organising medical institution, and if it happens, it becomes out approach of students from middle class families. Government can introduce subsidies/tax waiver for the import of infrastructure for the private institutions launching an academic programme with skill shortage.

Furthermore we recommend following regulatory measure that might be helpful in creating a trend in higher education compatible with national interests.

(a) If the subsidies given to students of management science (business administration and commerce) are withdrawn, this will not reduce the enrolment in these subjects significantly. This is because these subjects are usually adopted by the youth of economically stable families. Most of the students would continue their study of these subjects after removal of subsidies. In case if enrolment in these subjects is reduced (which is unlikely), this would not create any threat for economic growth of the country since there is abundance of skills in these subjects.

(b) If incentives/subsidies are given to universities for starting medical/engineering departments, this will create more opportunities for students to opt these subjects and thus reduce the skill shortage in these subjects. Government can introduce special incentive package for universities providing training in rare engineering skills e.g. space and electrical technology. For this government may seek recommendations from a board of professional engineers. Similarly, Government can introduce incentives for medical specialisations with severe skill shortage. 
(c) Agriculture and Live Stock sectors need serious attention of the Government. Despite of being an agricultural country, Pakistan imports a large number of agricultural products (wheat, sugar etc.) and input material for agriculture (seeds, fertilisers, pesticides etc.). To make these subjects attractive for a student willing to join a university, the Govt. should reduce gap between incentives available to a doctor, an engineer and a horticulturist. The existing centres of excellence in agriculture should be made more effective. The pay package and other incentives should be made as attractive for agriculturists as for bankers and management professionals. However to introduce these incentives for the professions with shortage of skills, Government does not need additional financial resources. The only job that Govt. has to do is, put those subjects on first priority while allocating funds in which there is shortage of skills.

\section{Costs and Benefits of Regulations}

The advantage of regulatory action is obvious; the country would have a skill supply more compatible with the requirement of nation. The cost of these regulatory actions is reduced incentives for the subjects with skill abundance. But these regulatory actions are unlikely to reduce enrolment in subjects with skills abundance since such subjects are usually chosen by pupil from established families and they can continue with their studies without seeking incentives from the Government.

\section{REFERENCES}

Awais, H. N. Tariq, H. R. Nawaz, and F. Ali (2008) The Role of Finance Institutions to Support Product-Oriented-Research at University Level in Metallurgy and Materials to Solve the Energy Crises in Pakistan. Paper presented in National Conferences on Socioeconomic Challenges Faced by Pakistan, International Islamic University, Islamabad.

Binnaz, Toprak (2006) Economic Development versus Cultural Transformation: Projects of Modernity in Japan and Turkey. New Perspectives on Turkey, Political Science and International Relations, Bogazici University.

Federal Bureau of Statistics (2005) National Educational Census, Pakistan.

Higher Education Commission (2005) Statistical Booklet of Higher Education Commission, Pakistan.

Infometrics Ltd. (2006) Indicators of Skill Shortage. Department of Labour, New Zealand.

Kelly, E., P. Connell and Emer (2008) The Economic Returns to Field of Study and Competencies among Higher Education Graduates in Ireland.

Kelly, E., P. Connell, and E. Smyth (2008) The Economic Returns to Field of Study and Competencies among Higher Education Graduates in Ireland. (ESRI Working Paper No. 242).

Skill Shortage Steering Committee (2006) National Skill Shortage Strategy for Local Governments. Australia.

Stevens, P. and M. Weale (2003) Education and Economic Growth. International Handbook on the Economics of Education. Edited by G and J. Johnes Edward Elgar.

Yong, Y. K., T. M. Heng, S. M. Thangavelu, and J. Wong (2007) Premium on Fields of Study: The Returns to Higher Education in Singapore. Department of Economics, National University of Singapore. (Paper No. 1/2007). 